\title{
AN EVOLUTIONARY STUDY OF THE BUTTERFLY MANIOLA JURTINA IN THE NORTH OF SCOTLAND
}

\author{
BRUCE FORMAN \\ Department of Natural History, Aberdeen \\ E. B. FORD and K. G. McWHIRTER \\ Genetic Laboratories, Department of Zoology, Oxford
}

Received I0.ix. $5^{8}$

A sERIEs of studies on the butterfly Maniola jurtina (Satyridæ) has demonstrated that the distribution of spotting on the underside of the hind wings can be used as a measure of evolutionary divergence between colonies of that species (Dowdeswell, Fisher and Ford, 1949 ; Dowdeswell and Ford, 1952, 1953, I 955 ; Dowdeswell, Ford and McWhirter, 1957 ; McWhirter, 1957). This work has been carried out in the Isles of Scilly and the southern half of England, augmented by a few samples from Ireland and the Isle of Man. In July 1956, one of us (Bruce Forman) with a party of students from the University of Aberdeen, visited Sutherland with the object of extending these investigations to a district in the far north. The samples so obtained were scored and analysed by E. B. F. and K. G. McW., so that the results should be strictly comparable with those published previously. The success achieved by the party was largely due to the care which they took to provide full and accurate observations on the habitats of the insect.

\section{DESCRIPTION OF THE LOCALITIES}

The work was carried out on the North Sutherland coast, on Rabbit Island (National Grid NC/6o26 $3^{*}$ ) and on the mainland opposite ; see the map, in which the various localities are indicated by the letters used in this account. Three colonies of sufficient size for sampling were found on the mainland. The most southerly of them $(\mathrm{K})$, near Kinloch Lodge, inhabited open spaces among birch woods. It was rather over an acre in extent and was traversed by the road from Tongue to Durness, which was no barrier to the butterfly. Part of the area had been a hay field and part was somewhat boggy. It was separated by two and a half miles from locality A. This comprised slightly less than half an acre along either bank of the Allt Loch Fhionnaich within a little gorge which is also crossed by the TongueDurness road. The sides of this gorge were occupied by trees, with open grassy spaces and some bracken. The whole was surrounded by moorland except at the eastern end where, north of the stream, a patch of bracken extended from the road down to well-cropped grass reaching to the shore.

$$
\text { * } 4^{\circ}, 24^{\prime}, 3^{\prime \prime} \text { west ; } 58^{\circ}, 3^{\prime}, 4^{\prime \prime} \text { north. }
$$


The third mainland locality (M) was approximately four miles farther to the north-cast, principally over moorland. It consisted of a number of gullies separated by low ridges running down to the shore;

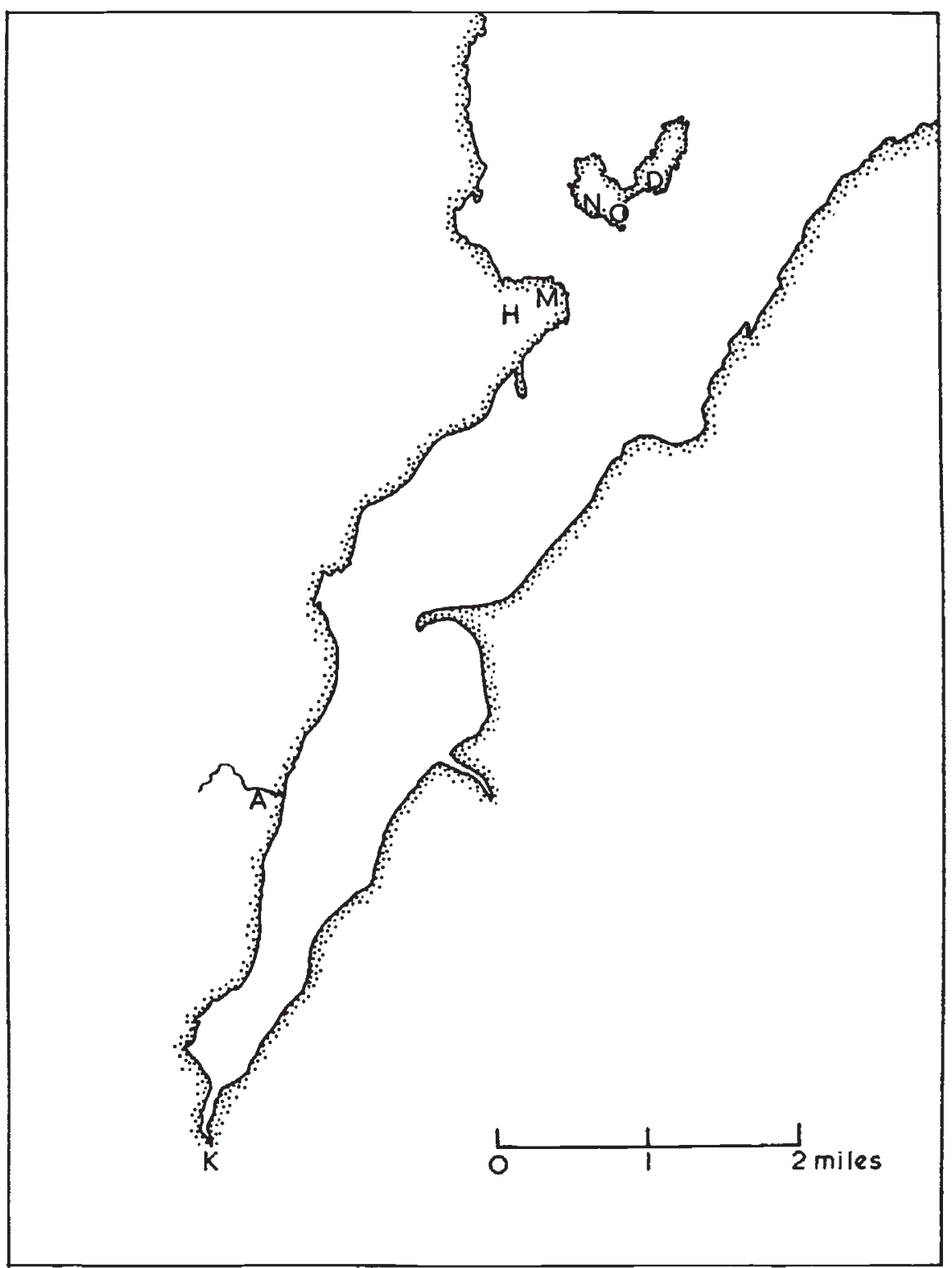

Map showing Kyle of Tongue, North Sutherland coast, Scotland, with Rabbit Island (National Grid NC/60263I). Localities are indicated by the letters used in the text.

in all, about an acre. Here the grass was short, with scattcred thistles and interspersed with considerable patches of bracken.

In addition, a few specimens were obtained in a hay ficld $(\mathrm{H})$ about one-third of a mile west-south-west of $\mathrm{M}$ and separated from it 
by higher ground with short turf where no butterflies were seen. However, the insects were here so rare that no effective sample could be obtained.

There can be little doubt that the principal mainland localities (and indeed that at $\mathrm{H}$ ) are isolated from one another ; for the butterfly seems absent from the intervening country, most of which appears to be quite unsuited to it, while in the circumstances the distances involved are far too great for it to traverse. Indeed repeated observations on the Isles of Scilly have shown that $5^{\circ}$ yards of unsuitable terrain form an effective barrier to this insect, though it can, and constantly does, travel farther than this in a few minutes within its own localities; so demonstrating the importance of minor ecological barriers to this, and we believe to many other, species.

Locality $\mathbf{M}$ is the nearest point on the mainland to Rabbit Island, from which it is separated by a channel, rooo yards across, consisting of tidal sand and a narrow strip of permanently open water. This island is in two parts, connected only by a bar of sand with some rocks, approximately 300 yards long, which remains uncovered at high tide. Upon the south-western portion, being that nearer the mainland, are two colonies of Maniola jurtina at $\mathrm{N}$ and $\mathrm{O}$ (see map). That at $\mathrm{N}$ faces across the channel to locality $\mathrm{M}$ and occupies about an acre. It is in the form of two gullies meeting behind a mound. The vegetation consists of grass, with bracken, nettles, thistles and primroses. To the east it is separated by a sandy valley, ro-2o feet deep and 20 yards wide, from area $O$. This is an irregular peninsula, of perhaps half an acre, with short turf and patches of bracken and primroses.

Colonies $\mathrm{N}$ and $\mathrm{O}$ are much too close to be isolated from one another. The rest of this part of the island is higher, relatively flat and exposed and, though not examined in detail, it was clear that the butterfly was not established upon it.

The north-eastern portion of Rabbit Island contained one colony only (D) of Maniola jurtina, at the end of the connecting sand bar. At this point two shallow gullies running inland from the shore meet behind a hillock, providing a locality very similar in shape and vegetation to that at N. Only a few scattered specimens were found farther on. This colony is almost certainly isolated from those at $\mathrm{N}$ and $\mathrm{O}$, being separated from them by 300 yards of sand, with a further I oo yards of unsuitable terrain (poor grass on sand from which the butterfly is absent) before reaching colony $\mathrm{O}$.

\section{THE SUTHERLAND DATA AND THEIR ANALYSIS}

The results of scoring the spot-numbers of the butterflies collected in each locality are shown separately for the two sexes in tables I and 2. A few additional specimens were obtained which were too worn to evaluate. 
The five specimens captured in locality $H$ (four males and one female) must be omitted, for it would be prejudicing the situation to combine them with the nearest effective sample (from $M$ ) since the

TABLE $\mathrm{I}$

Male spot-distributions per hind wing

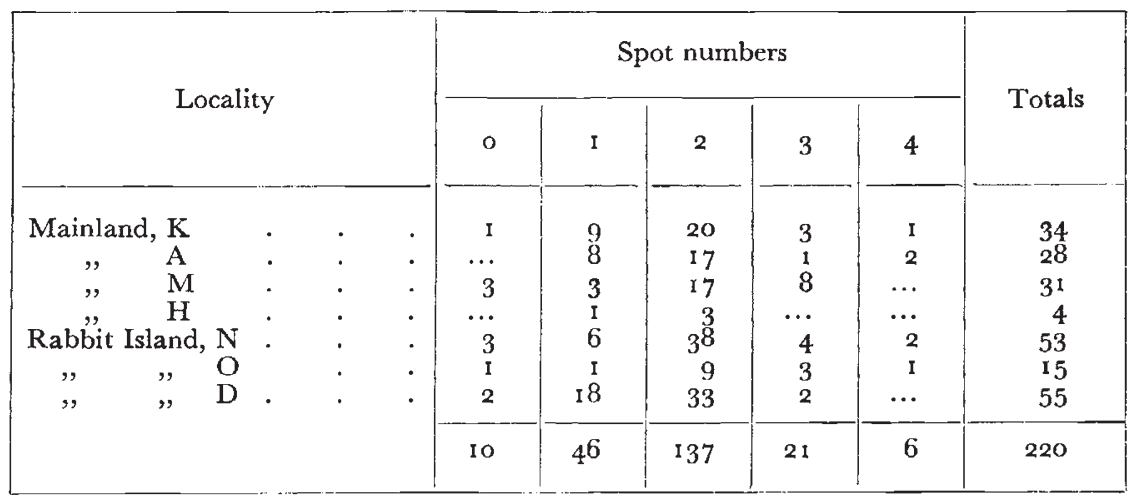

distance between the two places is certainly sufficient to provide isolation. We can therefore consider the three principal mainland samples, those from localities $\mathrm{K}, \mathrm{A}$ and $\mathrm{M}$. When testing the males for homogeneity the numbers are so small that only two groupings

TABLE 2

Female spot-distributions per hind wing

\begin{tabular}{|c|c|c|c|c|c|c|}
\hline \multirow{2}{*}{ Locality } & \multicolumn{5}{|c|}{ Spot numbers } & \multirow{2}{*}{ Totals } \\
\hline & o & $\mathrm{r}$ & 2 & 3 & 4 & \\
\hline \multirow{6}{*}{ 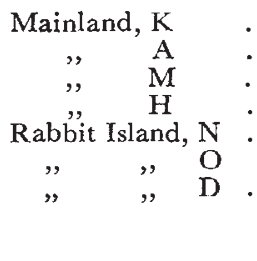 } & 21 & 8 & 3 & $\ldots$ & $\ldots$ & \\
\hline & 15 & 6 & 3 & I & $\ldots$ & 22 \\
\hline & 14 & 7 & 2 & $\cdots$ & $\cdots$ & 23 \\
\hline & 17 & 4 & r & I & $\cdots$ & $\begin{array}{l}1 \\
23\end{array}$ \\
\hline & $\begin{array}{r}6 \\
10\end{array}$ & $\begin{array}{l}\hat{y} \\
5\end{array}$ & $\ldots$ & $\ldots$ & $\ldots$ & $\begin{array}{r}7 \\
15\end{array}$ \\
\hline & 83 & $3 \mathrm{I}$ & 7 & 2 & $\ldots$ & 123 \\
\hline
\end{tabular}

of spots, $<2$ and $2+>2$ can be used. This gives $\chi_{\{2\}}^{2}=1 \cdot 02$, and $P$ between 0.7 and 0.5 . Similarly, the numbers are insufficient for more than two spot-groupings for the females; 0 and $>0$, for which $\chi_{(2)}^{2}=0.27$ with $P$ between 0.9 and 0.8 . Thus, though the colonies in these localities are isolated from one another, there is no indication in either sex of hetcrogeneity between them.

One of the two populations on the south-western portion of Rabbit Island, that from locality $\mathrm{O}$, is too small for separate treatment and, as it certainly cannot be isolated from that at $\mathrm{N}$, these are grouped 
together. When they are compared with the one at $\mathrm{D}$, in the northeastern division, a significant difference is found in male spotting, $\chi_{(2)}^{2}=9 \cdot 12$ and $P$ is 0.02 to $0 \cdot 01$. The number of females is so small that a considerable difference might exist between their spot-distributions on the two parts of Rabbit Island without being revealed by the present data. As these stand, $\chi_{\left({ }_{1}\right)}^{2}=0 \cdot I_{3}$ so that $P$ is approximately 0.7 and they are not heterogeneous. Clearly, however, having regard to the male situation, the reality of the female homogeneity cannot be assumed.

When we compare the total mainland captures, already shown homogeneous, with the total from the south-western part of Rabbit Island, we find substantial homogeneity for the entire assemblage in both sexes. The males provide a sufficient sample for a comparison using $<2,2$ and $>2$ spots. Here $\chi_{(2)}^{2}=2 \cdot 3^{8}$, with $P$ lying between 0.5 and 0.3 . The females can only be treated as individuals with 0 spots and those with I or more. They give $\chi_{(\mathrm{r})}^{2}=0.88 *$ with $P=0.5$ to $0 \cdot 3$.

There is thus evidence that in Maniola jurtina the three populations from the Scottish mainland, and that from the combined localities $\mathrm{N}$ and $\mathrm{O}$ on the nearer (south-western) part of Rabbit Island, are stabilised to a similar spot-distribution respectively in the two sexes, although the four habitats are isolated from one another. On the other hand, the adjustment of the butterfly to the conditions on the farther (north-eastern) section of Rabbit Island is significantly different as judged by male, but not by female, spotting.

\section{COMPARISON WITH MATERIAL FROM OTHER LOCALITIES}

\section{(i) The females}

Up to r $95^{2}$ the female spot-distributions of Maniola jurtina were of a constant pattern, with a single large mode at o spots, in all the Southern English localities so far studied from west Devon to the east coast. These include the transition from an Atlantic to a semi-Continental climate, alkaline and acid soils, with their widely distinct ecologies, and the vegetation both of poor downland and of rich meadows. It is evident, therefore, that in this region female spotting is stabilised to widely diversified conditions. Yet at the Devon-Cornwall border it changes abruptly to a different form : a bimodal one with a larger mode at o spots and a smaller at 2. Farther west in Cornwall, and on the Isles of Scilly, populations with other and highly characteristic spot-distributions are found (Dowdeswell and Ford, I953).

A more detailed analysis, however, showed that within the unimodal type of female spotting east of the Devon-Cornwall border, two subdivisions could be recognised. A more general one, the "Old English", with a relatively large mode at o spots, comprising 60 per

* Yates' correction is used in this and all other $\chi^{2}$ values with a single degree of freedom. 
cent. of the specimens or more, and another, the "New English", found in a few places only, in which the single mode at o is less pronounced, comprising 50 per cent. of the specimens or less.

By I956 the "New English" type had become more general in the region from Devon to the east coast, though some populations remained "Old English", while in a few instances a new spot-distribution, the "Pseudo-Cornish", had appeared. This has a second small mode at 2 spots in the females, reminiscent of the East Cornish

TABLE 3

Totals for Sutherland localities, $K, A, M, \mathcal{N}+O$, combined (excluding $D$ )

\begin{tabular}{|c|c|c|c|c|c|c|}
\hline Spots & o & I & 2 & 3 & 4 & Total \\
\hline Male & 8 & 27 & 101 & 19 & 6 & I $6 \mathrm{I}$ \\
\hline Female & 73 & 26 & 6 & 2 & $\ldots$ & 107 \\
\hline
\end{tabular}

type, which had not itself altered so far as our information extends. There is evidence that, in general, $M$. jurtina is now tending to return to the "Old English" state, with a single large mode at o in the females.

As already indicated, we have in the Sutherland data now available a stabilisation which transcends the considerable isolation of localities

TABLE 4

Southern English specimens from three localities (see text), 1956

\begin{tabular}{|lr|rrrrr|c|}
\hline Spots & $\cdot$ & 0 & 1 & 2 & 3 & 4 & Total \\
\hline Male & $\cdot$ & 6 & 22 & 133 & 44 & 9 & 214 \\
Female. & 191 & 84 & 35 & 5 & 2 & 317 \\
\hline
\end{tabular}

$\mathrm{K}, \mathrm{A}, \mathrm{M}$ and $\mathrm{N}+\mathrm{O}$ from one another. The combined spot-frequencies (already shown homogencous within each sex) are given in table 3 . It is surprising here to find, five hundred miles or so farther to the north, a situation characteristic of the greater part of Southern England, though that changes suddenly at the Devon-Cornwall border. For it will be seen that, in Sutherland, female spotting is unimodal at o and is of the "Old English" form, since specimens with o spots comprise 68 per cent. of the total.

This far northern collection may be compared with the south English samples of the "Old English" type captured the same year (1956), sce table 4. These are from three localities, Middleton East (Hampshire), Woolbury Ring (Hampshire), Newton Abbot (Devon). Their female spotting is homogeneous $\left(\chi_{1_{4}}^{2}\right)=6 \cdot 8_{3}$, for which $P=0 \cdot 2$ 
to $0 \cdot I$ ) ; the separate frequencies will be given in full in papers dealing specifically with the present situation in Southern England. These female samples may therefore be combined, and those from Sutherland are consistent with them : $\chi_{(2)}^{2}=3 \cdot 23$, with $P$ approximately $0 \cdot 2$.

The female spot-distributions of these Scottish insects are also similar $\left(\chi_{(2)}^{2}=3 \cdot 75\right.$, with $P 0.2$ to $\left.0 \cdot 1\right)$ to a widespread series of "Old English" samples taken in I952 at Ipswich, Winchester, Salisbury and Oxford. That group is homogeneous, with $\chi_{(6)}^{2}=5{ }^{\circ}$, giving $P$ from 0.5 to $0 \cdot 3$. (These data are from Dowdeswell and Ford, r953, table 2, from which Taunton is omitted since it is now known that it was then "New English" and in process of changing to the "PseudoCornish" type.)

\section{(ii) The males}

The Southern English males are unimodal at 2 spots. This arrangement is even more constant than is the female one of a single mode at $o$, being found so far as we know not only throughout the whole area from the east coast to west Devon, but also in Cornwall and, generally, in the Isles of Scilly. This is the more remarkable since male spotting is nevertheless capable of taking other values : for instance, unimodal at 3 spots in one island in Scilly and bimodal in an Irish locality. However, McWhirter (1957) has shown that significantly distinct male distributions exist within this highly constant general form and that there is a heavily significant correlation between the male and female conditions. Thus as the proportion of spotless females declines from the higher "Old English" value through the "New English" to the "Pseudo-Cornish", so the proportion of males with less than 2 spots decreases and that with more than 2 increases. Indeed male spotting, though so generally unimodal at 2, is more sensitive to minor evolutionary adjustments than the female, and serves to discriminate populations even within the three main Southern English groupings.

In the "Old English" stabilisation, in which 6o per cent. or more of the females are spotless, the proportion of males with I or o spots is together greater than, or approximately equal to, that with 3 spots or more. Sometimes, however, the latter group may amount to twice the number of specimens with less than 2 spots. In the " New English", and still more in the "Pseudo-Cornish" type, this excess at the higher spot values is much accentuated.

It will be seen from table 3 that the Scottish sample is markedly of the "Old English" type in both sexes. The males may be contrasted with those found in the three "Old English" populations captured the same year (1956) in Southern England.* These are homogeneous with one another $\left(\chi_{(2)}^{2}=1 \cdot 97\right.$, for which $P$ is 0.5 to $\left.0 \cdot 3\right)$. A comparison between the Scottish and English populations shows fairly clear male heterogeneity : $\chi_{(2)}^{2}=7.87$ with $P$ approximately $0 \cdot 02$.

* The individual data are being published separately. 
(iii) General comparison in both sexes

Since spotting shows much the greater degrce of minor diversity in the male scx, it is not surprising that the spot-frequencies of the Scottish and English populations captured the same year should be significantly different in the males cven though they are similar in the females. It will be noticed that the situation in Sutherland represents a slightly more extreme manifestation of the "Old English" type, for the spotless insects comprise 68 per cent. of the females, and males with less than 2 spots are $\mathrm{I} \cdot 4$ times as common as those with more than 2. Indeed in both sexes a progressive gradient towards lower spot-values is detectable from localities arranged in the order : East Cornwall, Southern England (east of Cornwall), Sutherland, the Isle of Man, Galway (Ireland). However, one of the most important discoveries which results from collccting Maniola jurtina in Sutherland is the fact that the females there are unimodal at o spots. This clearly suggests a similar adjustment over the greater part of Britain, though it is one which can be broken down abruptly when a different type is favoured, as at the Devon-Cornwall border.

\section{SUMMARY}

(I) Samples of the butterfly Maniola jurtina have been collected from five localities in North Sutherland. Three are on the mainland and two are respectively on the two parts of Rabbit Island which are connected with one another only by a bar of sand.

(2) The populations in these localities are all isolated from one another. Two habitats ( $\mathrm{N}$ and $\mathrm{O}$ ) upon the south-western portion of the island form a non-isolated unit which can be combined. The individuals caught in an additional mainland locality $(\mathrm{H})$ are too few for analysis.

(3) Previous work has proved that spotting in this species, which takes different distributions in the two sexes, provides a sensitive criterion of evolutionary adjustment.

(4) Using that character, the three mainland populations and the one on the nearer (south-western) part of Rabbit Island prove to be homogencous.

(5) The population on the more remote (north-eastern) part of the island has been independently adjusted to that habitat, being significantly different from the others, judged by the male spotdistribution. Too few femalcs were obtained to provide an effective comparison in that sex.

(6) The males in Sutherland are unimodal for 2 spots like all Southern English communities, including the Cornish localitics (which are distinct from the rest of the country in the female sex). Minor but significant differences in the distribution of male spotting occur within this unimodal form, and in this respect the Sutherland males differ significantly also from the Southern English ones. 
(7) In certain South English habitats the species has undergone a significant change since $195^{2}$ which, indeed, was already apparent in a few places in that year. The Scottish samples represent a somewhat more extreme phase of the former Southern English stabilisation, from which certain of the English populations have not diverged and to which the others appear to be returning.

(8) The Sutherland insects in both sexes tend to conform, though in a less degree, to the type with relatively few spots found in the Isle of Man and in Galway, Ireland.

(9) Female spotting, which takes various distinct forms in Cornwall and the Isles of Scilly, is generally adjusted to a uniform type (unimodal at o spots) in Southern England, where it is stabilised throughout a wide range of climatic and ecological differences.

(Io) The Scottish samples, though caught five hundred miles farther north, are similarly stabilised, being unimodal at o spots in the female. This is the more remarkable since that condition alters abruptly to a bimodal one at the Devon-Cornwall border.

\section{REFERENCES}

DOWDESWELl, W. H., FISHER, R. A., AND FORD, E. B. 1949. Heredity, 3, 67-84.

DOWDESWELl, W. H., AND FORD, E. B. 1952. Heredity, 6, 99-109.

DOWDESWELL, W. H., AND FORD, E. B. 1953. Symposia Soc. Exp. Biol., 7, 254-273.

DOWDESWELL, W. H., AND FORD, E. B. 1955. Heredity, 9, 265-272.

DOWDESWELl, W. H., FORD, E. B., AND MCWHIRTER, K. G. I 957. Heredity, II, 5 I-65.

MCWHIRTER, K. G. 1957. Heredity, II, 359-37I. 